\title{
Effect of Direct and Indirect Teacher Feedback on Accuracy of English Writing: A Quasi-Experimental Study among Pakistani Undergraduate Students
}

\author{
AASIA NUSRAT \\ Department of Humanities, \\ COMSATS University, Lahore, Pakistan \\ aasianusrat@cuilahore.edu.pk \\ FARZANA ASHRAF \\ Department of Humanities, \\ COMSATS University, Lahore, Pakistan \\ MARIE FRANCOISE NARCY-COMBES \\ University of Nantes, France
}

\begin{abstract}
Introducing new techniques to improve learner-teacher interaction receives substantial attention from the field of educational psychology. The current research aims to investigate the effect of teacher feedback on the written English accuracy of English as Second Language (ESL) students. In a quasi-experimental study, 90 participants were given three distinct forms of feedback (i.e. oral meta-linguistic, also called direct feedback; written indirect feedback and no feedback) for writing errors of three types (i.e. verb tenses, use of articles and prepositions) and were assessed three times during the study (i.e., pre-test, immediate post-test and delayed test). One-way ANOVA demonstrated that the ESL learners given direct meta-linguistic oral feedback reported fewer errors in two out of the three linguistic forms in subsequent writing in comparison with ESL learners who received indirect written feedback and those who did not receive feedback. Findings suggest that introducing oral meta-linguistic teacher feedback in the Pakistani language learning context can improve the English language learning of students.
\end{abstract}

Keywords: ESL learners; oral meta-linguistic feedback; indirect written feedback; written accuracy; direct feedback

\section{INTRODUCTION}

Teacher feedback is one of the most important tools in any form of learning, particularly in language learning. Research indicates the crucial impact of teacher feedback on successful learning, especially in learning a second/foreign language. Albeit an official language in the multilingual context of Pakistan, English is used as a second language. Urdu is the national language of the country. This situation can result in the nativisation of the target language because learners fail to acculturate properly to the norms of the language (Schumann 1978). As the language of power, English is mandatory for higher education, whilst English (mostly in private schools) and Urdu (mostly in public schools) are used as medium of instruction at the school level (Coleman \& Capstick 2012). Both languages are the examples of modified diglossia, that is, the two languages are used more or less for formal purposes. In Pakistan, English is the dominant language in the domains of civil and military bureaucracy, law, commerce, media, education and research (Sarwar et al. 2012). Pakistani English varies from standard British English at various levels (e.g. phonological, morphological, syntactic, lexical and semantic) (Rahman 1990). These variations impact the written production of Pakistani students, who are likely to resist corrective feedback because the English language they use is quite different from the English language instructed to them. Teacher feedback is generally 
seen as a valuable tool for developing students' target-like competency in English writing (Bitchener \& Knoch 2008).

In Pakistan, English is taught as a compulsory subject from grades 1 to 14 . However, Pakistani students have difficulty in mastering and accessing the standard variety of English to obtain higher education or find a good job. Therefore, investigating the acquisition of English language is difficult as the context of learning is very complex. Hence, many difficulties are due to confounding factors which include inappropriate textbooks and course materials (Siddiqui 2007), low English competency levels of teachers (Haider 2012) and use of traditional approaches for teaching grammar. The Teachability hypothesis of Pienemann (1989) emphasises the need for compatible course contents to be taught in accordance with the learners' developmental need. This notion seems to be missing in the Pakistani context because existing academic system does not have formal structures for measuring and assessing the developmental needs and cognitive abilities of learners in general and language courses in particular (Siddiqui 2007). However, teacher feedback could be used to help learners develop cognitive skills and obtain advantage by learning from and incorporating the feedback to improve their writing accuracy.

Moreover, instructor feedback could improve the cognitive aspect of learners' skill development that cannot be overlooked. Robins et al. (1997) reveal that learners perceive corrective feedback as the key to healthy learning environment. Useful feedback comprises information provided to learners for reinforcing appropriate and correcting inappropriate efforts. Feedback is an essential, but often neglected part of the educational process.

\section{LITERATURE REVIEW}

In the literature review section, different empirical studies are discussed with respect to the effectiveness of feedback in general and its specific types in particular.

\section{EFFECT OF FEEDBACK ON WRITING ACCURACY}

Truscott (1996) questioned whether learners learned linguistic forms in actual practice when they receive corrective feedback or they were just using the target linguistic structures without having knowledge about their rules. First, he claimed that learners exhibit improved performance after receiving corrective feedback, but they lost the gained knowledge after a few weeks or months (Truscott 1996). Thus, corrective feedback is responsible for pseudolearning. The second reason why Truscott (1996) refuted that error feedback plays a significant role in learning because early studies were based on inaccurate designs. In contrast to previous works (e.g. Ferris \& Roberts 2001; Chandler 2003), recent research concluded that written feedback can be effective for improving the accuracy level of grammatical items in new pieces of writing (e.g. Bitchener, Young \& Cameron 2005; Bitchener 2008; Bitchener \& Knoch 2008, 2010; van Beuningen, Jong \& Kuiken 2012). These studies also noted and tried to avoid the limitations in the design of earlier studies (e.g. absence of a no-correction control group and comparison between the initial samples and new texts as well as limited assessment of longitudinal effectiveness). According to Guenette (2007), comparison is difficult due to these inaccuracies and limitations in design features of previous studies. In the correction-no correction control group, Ferris (2004) agreed that comparison of students is made between those who have received correction and those who have not. Ferris claimed, 'If correction is important for learning, then the former students should be better writers, on the average, than the latter' (p. 50). 
Previous studies (e.g. Lalande 1982; Robb, Ross, \& Shortreed 1986) did not include a no-feedback control group, but others did (e.g. Kepner 1991; Polio, Fleck, \& Leder 1998; Ferris \& Roberts 2001) and still showed flaws in their design. For instance, Kepner (1991) did not include a pre-test measurement. In Polio, Fleck, and Leder (1998), different instruments were used in the two tests, increasing the chances that instrument variability might have had an impact on its findings. Ferris and Roberts (2001) compared the feedback versus non-feedback group, but both groups were not comparable in terms of learners' proficiency levels.

The other aspect is concerned with the measurement of accuracy in new pieces of writing. To measure the effectiveness of feedback, a pre-test is required to compare the results with the immediate and delayed post-tests. Ferris (2004) considered both measures important when he argued that 'It is assumed that both measures are important-the former because it helps to assess student uptake of corrections received and the latter because it provides evidence as to whether the input has been not only comprehended on the spot but acquired as part of the learners' developing competence in the L2.' (p. 54).

Among the above studies that had a control group, only Kepner (1991) and Polio, Fleck and Leder (1998) were longitudinal. The study of Ferris and Roberts (2001) was of short duration or cross-sectional and merely engaged in the revision of text rather than the new pieces of writing. Hence, no post-test writing was involved as part of the study for finding out the effect of feedback over time. Studies that had longitudinal research design showed that the linguistic accuracy of learners did not improve, except the work of Chandler (2003) which did not include a non-correction control group. Therefore, the reliability of these previous works might be questionable.

Apart of the aforementioned flaws, previous studies did not focus on identifying problematic forms. Instead, they focused on problematic forms found in previous studies and in different contexts. No revision stage in these studies before the post-tests draw the learners' attention to the teachers' feedback, which they could use to correct their errors themselves and thus improve their writing (Ferris 2010). Therefore, the current study followed a pre-intervention - feedback + self-editing post-intervention - research pattern. The present study aims to engage and motivate the students to perform corrections based on their teachers' feedback and to determine if the inclusion of the revision/self-correction stage would make any difference in the acquisition of certain linguistic forms over time. Different groups of students were compared. Among which, two were given different kinds of feedback, and one received no feedback at all.

\section{EFFECTIVENESS OF TYPES OF FEEDBACK ON WRITING ACCURACY}

Error feedback studies have used two broad types of feedback, namely, direct (oral) and indirect (written). Using direct feedback, the teacher provides the correct expressions, whilst the students are supposed to internalise and then transfer the correct forms to their subsequent writing. By contrast, indirect feedback requires students to correct the errors identified by their teachers, who do not provide the correct form (Ferris \& Roberts 2001). Indirect corrections, where learners are encouraged to self-correct by highlighting the errors or identifying the category of error with a code, are preferred as the learners are involved in cognitive problem solving. Meanwhile, direct corrections, where correct form is provided, might be effective for low-proficiency learners or those dealing with specific categories of errors (Aljaafreh \& Lantolf 1994; Bitchener, Young \& Cameron 2005).

Robb, Ross and Shortreed (1986), Chandler (2003) and van Beuningen, Jong and Kuiken (2012) compared direct with indirect feedback in written form. However, these studies did not investigate oral meta-linguistic explanation, which is another form of explicit 
or direct feedback. Oral meta-linguistic explanation takes the form of classroom discussion or a short lesson where the teacher provides linguistic rules along with explanatory instances to help students understand and apply the rules to improve their accuracy. Discussions can take place in one-on-one teacher-student conferences (Bitchener 2008; Bitchener \& Knoch 2009a) as well as in groups or with the whole class.

Previous studies (e.g. Bitchener, Young \& Cameron 2005; Bitchener 2008; Bitchener $\&$ Knoch 2008) compared direct oral feedback with written direct feedback and measured the effect of different amounts of time spent and the nature of the errors. For instance, the duration of oral feedback in Bitchener, Young and Cameron (2005) was 5 minutes. By contrast, Bitchener (2008) and Bitchener and Knoch (2008) extended the time to 30 minutes. Bitchener, Young and Cameron (2005) focused on three grammatical areas, namely, articles, past tense and prepositions. Bitchener (2008) and Bitchener and Knoch (2008) focused on only one linguistic form (English article) to discover the effect of written and oral feedback on accuracy over three and two months, respectively. The findings of the two studies indicated positive effects of teacher-students conferencing along with written (direct) feedback on a new piece of writing. However, Bitchener and Knoch (2008) indicated that both feedback types had similar effect. These studies found that oral (direct) and written direct feedback on the improvement of articles and past tense errors positively affected learners, but no significant improvement was seen in the case of prepositions. These results were in accordance with the findings of Ferris and Robert (2001) that students were generally more capable of editing rule-governed categories (like verb tenses) than idiosyncratic categories that must be learned individually (like prepositions). The former is considered treatable, whereas the latter is untreatable (Ferris 1999).

Bitchener and Knoch (2009a, 2010a) assessed the effect of feedback on the accuracy of articles over 6 and 10 months, respectively. In contrast to the abovementioned studies (e.g. Bitchener, Young \& Cameron 2005; Bitchener 2008; Bitchener \& Knoch 2008), one of these two studies (e.g. Bitchener \& Knoch 2009a) had no no-correction control group. Both studies found no difference in the three treatment groups. Therefore, direct written feedback is equally significant for improving the accuracy of articles, which was similar to that of the group with oral metalinguistic feedback. In a more recent study, Luan and Ishak (2018) found the positive long-term effect of both direct and indirect written feedback in improving students' accurate use of past tenses over a period of three weeks.

The above studies focused on direct written feedback type. However, the use of oral metalinguistic feedback must be investigated in comparison to other types of written feedback (i.e., indirect, where mistakes are indicated, but the correct form is not given) to determine which, if any, is more effective. Bitchener and Knoch (2010b) is the only study to compare indirect with oral direct feedback to discover any effect on the accuracy of articles over 10 weeks. This time, the duration of teacher's oral feedback was 15 minutes. Bitchener and Knoch (ibid) revealed that treatment groups outperformed the control group in the immediate post-test. On the delayed post-test, after 10 weeks, the oral direct feedback groups outperformed the indirect written feedback group. Hence, these findings exhibited the superior longitudinal effect of providing learners with oral meta-linguistic explanation rather than indirect feedback that only provided information about the location of errors. The current study, therefore, used indirect rather than direct written feedback to compare with teacher oral feedback to students. Further, the study aims to discover if indirect written feedback alone could enable learners to improve the accuracy level of targeted error and/or if accuracy levels can be improved using oral meta-linguistic feedback alone.

The potential use of such feedback is significant in the Pakistani context, where mostly teacher-dominated feedback is given on students' performance, and this strategy demotivates and induces little interest among students to take note of that feedback to 
improve (Haider 2012). The communication gap between teachers and students intrudes in discussing their errors due to lack of time, meta-linguistic knowledge, or both. As such, teachers mostly use direct written feedback to point out each error (Haider, ibid). Teachers are responsible for editing their students' written texts, which is a time-consuming job. Moreover, teachers cannot fully concentrate on providing adequate feedback on every error, and thus they have to overlook some of the errors or mistakes that they come across while checking the written texts of their students. Therefore, the current study investigates the effectiveness of feedback and its types (written and oral feedback) in improving learners' written accuracy concerning targeted second language (L2) linguistic forms.

\section{THEORETICAL BACKGROUND OF THE STUDY}

Along with empirical investigations, many theoretical guidelines emphasised the need for teacher feedback and their awareness of student needs and associated benefits. For example, in the classical socio-cultural theory of Vygotsky (1978), learning is associated with the zone of proximal development (ZPD). ZPD is identified by the teacher as the step above the learner's current capability which they use in planning appropriate content. In this study, direct oral feedback is provided as a form of guidance to the learners. Interaction with an expert (teacher) helps novice (students) enter into their ZPD. This situation allows learners to move from interpsychological to intrapsychological level, and internalisation occurs to help students transform into independent language learners. ZPD was later investigated by Pienemann (1989), who highlighted the need for course contents compatible with the learners' developmental needs. In an extension to that claim, interaction theory (Long 1996), underpinning oral meta-linguistic direct feedback, suggests that the interaction of students with their teacher helps them to pay attention to forms. In effect, students respond by producing written output themselves. In this study, the learners produced three written texts at three different times after receiving feedback, which ultimately improved writing accuracy (Swain 1995).

Moreover, in socio-cultural perspective, scaffolding between a teacher and a learner in the form of oral meta-linguistic conferencing can move learners from the interpsychological (social) to intrapsychological (individual, internal or potential) level when they successfully produce new, accurate pieces of writing after internalising teachers' feedback. Hence, this knowledge transfer can be produced by other regulations (Aljaafreh \& Lantolf 1994), which can be oral meta-linguistic feedback, as in the case of the current study.

According to most researchers, acquiring competence in L2 is a matter of triggering implicit knowledge (which is procedural and claimed to be unconscious and non-verbalised) through the use of explicit knowledge (Bailystok 1994). Explicit knowledge refers to the declarative and conscious knowledge of grammar rules that can be verbalised and labelled using appropriate meta-language (Ellis 2004). If such explicit information in the form of written and oral feedback leads to learners producing accurate linguistic forms and ultimately converts explicit knowledge into implicit knowledge, then such evidence could be compatible with a strong or a weak interface position (DeKeyser 2003). If feedback does not indicate any development of implicit knowledge, then this situation would be evidence of the noninterface position (Truscott 1996). Thus, no link exists between knowing about a language (extrinsic knowledge, e.g. of grammar rules) and using it to communicate through intrinsic knowledge which comes from practice. The knowledge used by learners depends on the type of task they perform (Ellis 2005). In the current study, students were required to produce free writing, that is, freely constructed responses where the learners are required to produce the target language without any constraint (Norris \& Ortega 2000). The free writing is based on pictures that could tap into their intuitive awareness of implicit grammatical rules (Ellis, 2005). These tasks aimed to identify if the explicit knowledge provided in the form of 
indirect written and direct oral feedback after the free writing task could be converted into implicit knowledge used in new pieces of writing.

\section{RATIONALE AND HYPOTHESIS OF THE STUDY}

The current research has made an effort to overcome the research gaps found in previous empirical studies concerning their flaws in design and execution. Based on the study's rationale, empirical studies and theoretical orientations, the hypothesis is that teachers' feedback (both oral and written) is likely to support the students' language learning proficiency. Moreover, students who receive direct oral feedback are likely to perform better and commit fewer errors than students who did not.

\section{METHOD}

\section{RESEARCH DESIGN}

A pre-, post-test quasi experimental design was used in the current study. This design was adopted given the objective of the study which is to compare the effect of different teachers' feedback (no, oral, and written) on students' learning of L2 linguistic forms at three points in time (pre-test, immediate post-test and delayed post-test).

\section{PARTICIPANTS OF THE STUDY}

The participants in the study were 90 undergraduates from BZU (Baha-uddin-Zakariya) University. They were enrolled in the Department of Humanities studying different social sciences disciplines, namely, psychology $(n=21)$, economics $(n=25)$, history $(\mathrm{n}=22)$ and Islamic studies $(n=22)$. Appropriate representation of each class of students from different social science disciplines were performed through random assignments of learners across three groups. The same language teacher was appointed for each of the three classes. The participants were aged between 19 and $23(M=21.11, S D=1.19)$, with $18 \%$ male and $82 \%$ females. The majority of participants were females due to the similar overall disproportionate gender distribution across the social sciences. All these participants were bilingual, and English was their second language. To control for the effect of any confounding variable, all participants who were speakers of languages other than English and their mother language were excluded. Corollary to this condition, participants whose first language was English were excluded. Only participants from the social sciences as well as applied science discipline were considered because they took great care of the content rather than the form while writing English language. Other exclusion criteria were any significant and diagnosed speech or language deficiency or disability, and other neurological or psychological conditions reported in the previous six months.

\section{RESEARCH INSTRUMENTS}

The research instruments have two parts: teachers' feedback and assessment of students' learning.

\section{ASSESSMENT OF STUDENT LEARNING}

Three sets of picture prompts for narrative writing taken from Fletcher and Birt (1983) were used to prompt the students to produce a sample of written text before administering any of the three interventions (i.e., no, oral and written feedback). To avoid practice effect of 
producing the same errors in same type of writing, three different picture prompts, namely, A, B and C, were administered on the same sample at three different points in time. Each set of picture prompts consisted of a series of pictures telling a story. The students were required to explain what was going on in the pictures. The students were asked to write a story based on each set of picture prompts using a minimum of 100 words in 20 minutes. Accuracy in the use of three linguistic forms (articles, prepositions and past simple tense) was measured over three months by employing a pre-test, immediate post-test and a delayed post-test written exercise administered after two months using the three sets of picture prompts. The participants were first given 20 minutes to create a writing sample based on the description of the first series of pictures. The time duration of 20 minutes meant that students had to produce writing under time pressure and use their implicit knowledge of grammatical forms (Ellis 2005). Errors were classified into articles (e.g. a, the "Once there was the fat man....The fat man did not realize that there was dog in the street...Dog barked at that moment"), prepositions (e.g., on, in, at, to "he looked himself on the mirror. In the way, he found that....") and simple past tense errors (e.g. regular and irregular English past-tense forms "Once upon a time, there was a fat man. One day, he sees his reflection in the mirror...").

\section{TEACHER FEEDBACK}

Teacher feedback mainly involved indirect written (Group 2) or direct oral meta-linguistic (Group 1) feedback. It is adopted in the study because it is the dominant feedback in the Pakistani ESL-learning context (Haider 2012). Hence, both types belong to teacher rather than peers to find out whether it would be indirect written or direct oral feedback that could decrease their load of work in terms of correcting students' texts. The indirect written feedback involved circling, underlining or using error codes for the wrong usage of three types of errors. The oral feedback comprised a 20-minute mini-lesson in which rules were explained along with examples provided on whiteboard. Additional examples were discussed with the students. Students were then asked to complete a six-minute controlled practice exercise where they had to fill in the gaps for different sentences with articles, prepositions and past tense of verbs. The answers were then discussed with the learners.

\section{PROCEDURE}

Undergraduates at the university are offered English courses in first year of their two years of an MA programme. All the heads of department were contacted and briefed about the objectives, scope and significance of the study. The 90 students recruited were well distributed across the four previously mentioned disciplines and informed about the schedule for the administration of the interventions to ensure that the participants did not skip classes to be part of the study. Confidentiality of provided information to be used only for academic purpose was assured. Participants were briefed about their right to withdraw from participating at any point in the study if they wanted to.

One week before the administrating of first intervention, the students and teachers of the three groups were provided with the assessment material (i.e. instructions and pictures for pre-intervention assessment). The pre-test was carried out in the first week of the experiment, and the students' writing was photocopied twice before correcting their pre-test writing. One set was given to a language teacher to mark the errors while the other set was marked by the researcher to produce a reliability check. Throughout the whole procedure, the same teacher and researcher marked all three sets of writing from each of the three groups to maintain consistency. The marking of all the students' written errors was completed in the second week of the experiment. The frequency of each error category was counted, and the most frequent errors were collected as the main focus of this study. 
In the third week, the pre-test writing of participants was returned to Group 2, which received indirect written feedback provided on the three error categories, highlighting the most recurrent errors and students were asked to self-correct the writing errors in their scripts. Group 1 received a 15- to 20-minute lesson on the same three most frequent errors (oral meta-linguistic explanation) before they started their self-correction. Group 3 was asked to correct their errors by themselves without having any feedback either written or oral. The second piece of writing for all three groups, based on the second set of picture prompts, took place in the following week (week 4) to see any improvement or transfer of the knowledge given from the feedback to Groups 1 and 2 in their written accuracy of the three types of targeted errors. After a week, this second piece of writing with indirect feedback was given back to Group 2. Group 1 received direct oral feedback once they received their second written texts. To identify if any of the feedback had been effective over time, a delayed postintervention test was administered five weeks later. The third sample of writing was given back to the participants along with written indirect feedback to Group 2 and direct oral feedback to Group 1 one week after the delayed post-test for self-correction. During the interim period, normal instruction continued.

\section{DATA ANALYSIS}

The data were produced at three different times (i.e. pre-test in week 1, immediate test in week 4 and delayed post-test in week 12). The between-participant factor was feedback at three levels (written only, oral meta-linguistic lesson and none). For each combination, the students were focused on accuracy/errors and their performance was measured as an error ratio or an error rate per type over the three pieces of writing. Students' compositions varied in the number of words they used. To control for this factor, the error rate was calculated as the total number of errors/total number of words $\times 100$.

Each occurrence of incorrect, omitted or unnecessary usage was counted as an error. The mean and standard deviations for the three targeted forms for each of the three pieces of writing were calculated for each intervention Groups (1, 2 and 3). Statistical significance was assessed through one- and a two-way repeated measure ANOVA. The one-way ANOVA with Tukey's post hoc pair-wise comparison was performed to isolate the exact points in time when differences between the groups occurred. For this purpose, SPSS version 18 was used. A reliability level of 0.84 was gained for the categorisation and identification of errors in the pre-test writing. Using the three targeted error types, correlation coefficients of 0.80 and 0.79 , respectively, were obtained for error counts in the samples written soon after the pre-test and those written after two months, and the correlation coefficients were 0.91 and 0.90 , respectively, for error assignment/marking in the second and third writing samples.

\section{RESULTS}

Table 1 shows the summary of the descriptive statistics for all three targeted linguistic forms (taken collectively). Figure 1 graphically presents the means of the three groups for each of the three targeted linguistic forms over time. Three error categories were the focus of this study because these linguistic forms, namely, articles, prepositions and verb tenses, were problematic for learners as the most frequently occurring errors in their pre-test writing with a percentage error score of $19 \%, 17 \%$, and $12 \%$, respectively. 
TABLE 1. Descriptive statistics: the number of three targeted errors types per 100 words (accuracy) across the different groups over time

\begin{tabular}{|c|c|c|c|c|c|c|}
\hline \multirow[t]{2}{*}{ Groups } & \multicolumn{2}{|c|}{ Pretest writing } & \multicolumn{2}{|c|}{ Immediate post-test } & \multicolumn{2}{|c|}{ Delayed post-test } \\
\hline & $M$ & $S D$ & $M$ & $S D$ & $M$ & $S D$ \\
\hline Oral Feedback & 5.64 & 1.35 & 4.40 & .87 & 4 & .91 \\
\hline Written Feedback & 5.40 & .91 & 4.72 & .94 & 5.08 & 1.04 \\
\hline No Feedback & 5.32 & .85 & 5.84 & 1.03 & 5.64 & 1.08 \\
\hline
\end{tabular}

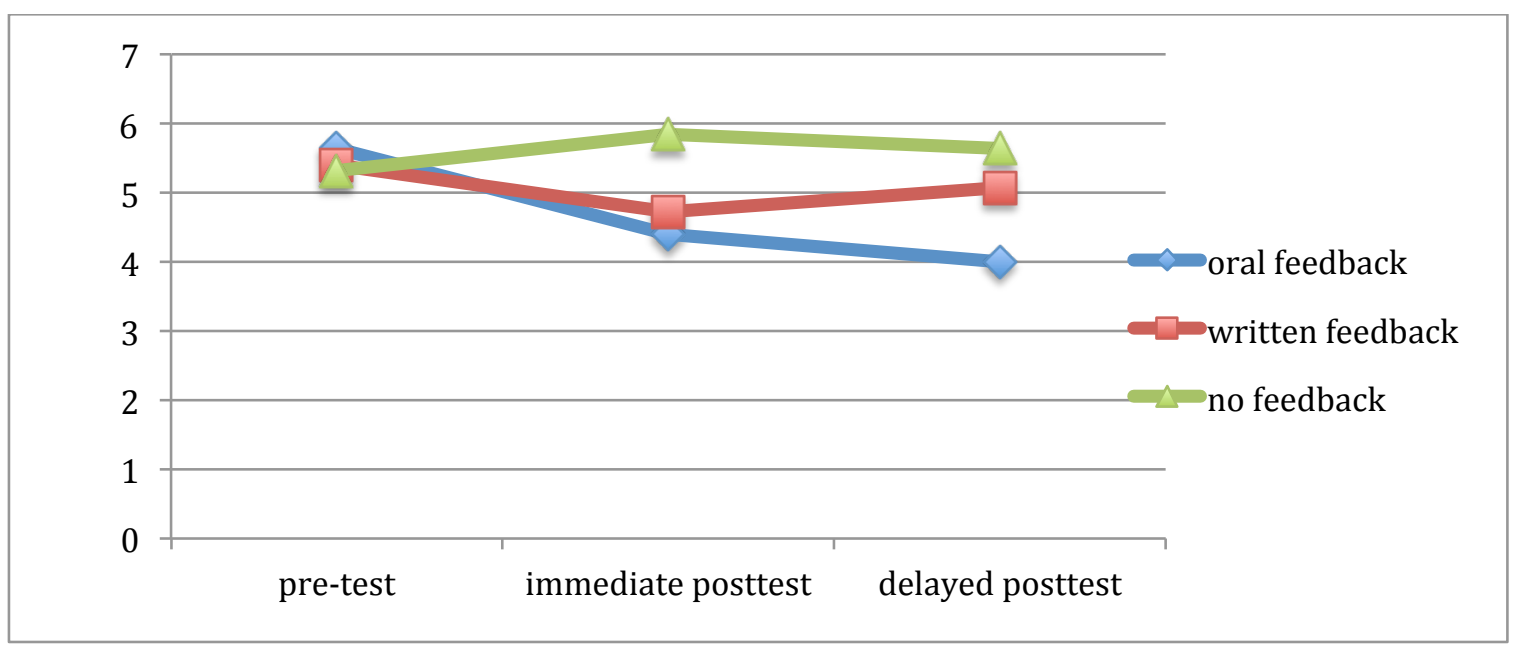

FIGURE 1. Group mean use of the three linguistic forms across the three treatment groups over time

Figure 1 suggests that the students in Group 1, who received oral meta-linguistic explanations, and Group 2, who received indirect feedback, outperformed the control group who did not receive any error correction. A one-way ANOVA revealed significant differences in the mean number of errors for the three groups $(F=9.34 ; p=0.000)$. Tukey's pairwise comparisons further indicated that differences were found between Group 3 (control group) and Group $1(p=0.000)$ but not between Groups 2 and $3(p=0.072)$. Tukey's pairwise comparisons further revealed significant differences between Groups 3 and 1 ( $p=$ $0.000)$ and Group $2(p=0.048)$ in the immediate post-test. However, in the delayed post-test five weeks after the feedback intervention, Group 3 showed a significant difference from Group $1(p=0.000)$ but not from Group $2(p=0.191)$.

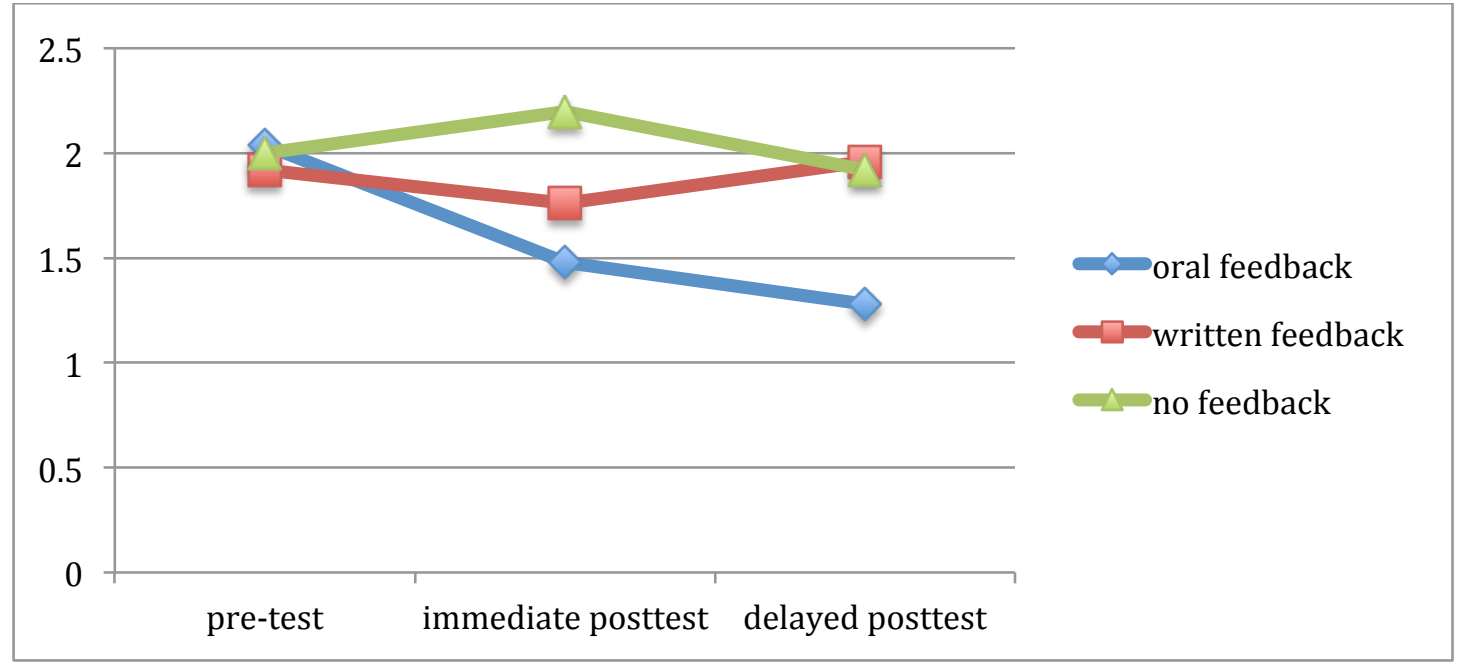

FIGURE 2. Group means for the use of article errors across groups one, two and three over time 
As shown in Figure 2, the mean number of article errors in experimental Groups 1 and 2 decreased in the immediate post-test. Group 3 produced more article errors during the immediate post-test but fewer errors during the delayed post-test compared to their pre-test mean scores. A one-way ANOVA revealed significant differences in the mean number of article errors for all three groups $(F=5.49 ; p=0.001)$. Tukey's pairwise comparisons further indicated differences between Groups 3 and $1(p=0.001)$, but not between Group 2 ( $p=$ $0.486)$. The ANOVA test found the three groups differed from each other $(F=4.3 ; p=$ $0.015)$ in the number of article errors they produced. The pairwise comparisons revealed Group 3 had significant differences compared to Group $1(p=0.002)$ but not to Group $2(p=$ 0.122 ) in the immediate post-test. Likewise, in the delayed post-test, significant differences were found between Groups 3 and $1(p=0.007)$. Of the two intervention groups, Group 1 outperformed Group $2(p=0.004)$ in the delayed post-test.

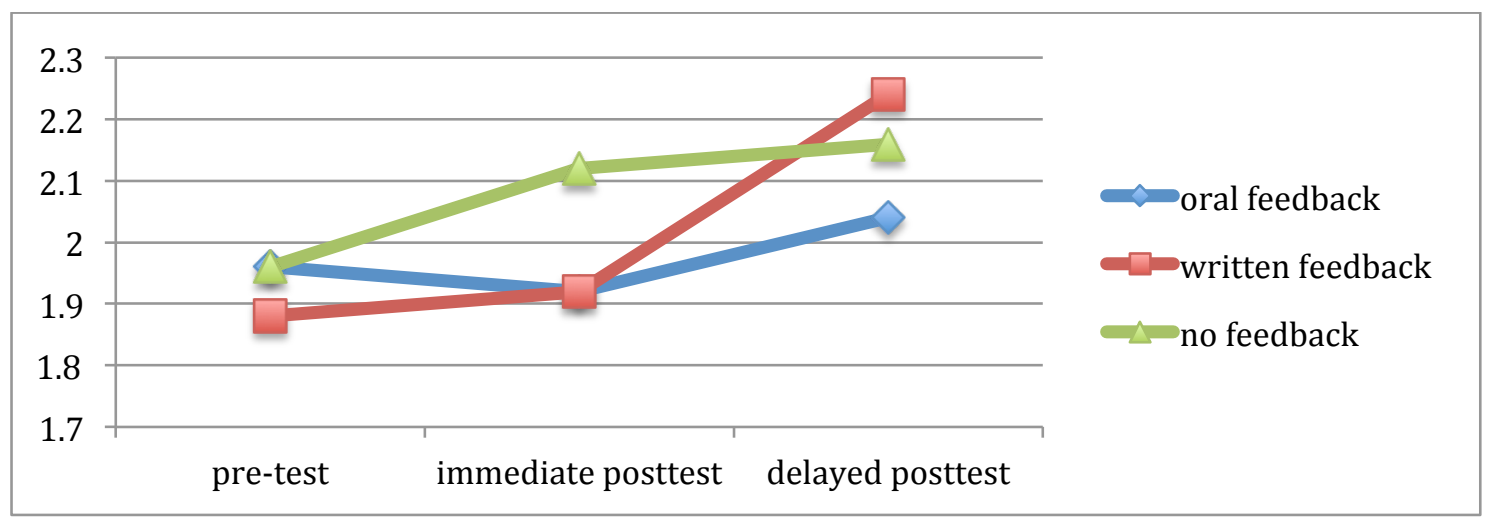

FIGURE 3. Group means for the use of preposition errors across the three treatment groups over time

Figure 3 indicates that the mean number of preposition errors increased consistently in Groups 3 and 2 in the samples written soon after the pre-test sample and after two months. Groups 1 and 2 produced a fairly similar number of errors in the immediate post-intervention but in their third post-intervention writing, the number of errors in both groups increased. A one-way ANOVA test revealed equal development in the number of preposition errors for all three groups $(F=0.335 ; p=0.800)$. Pairwise comparisons revealed no significant difference between any two groups.

A one-way ANOVA further revealed significant differences in the delayed post-test $(F=9.47 ; p=0.000)$, but not in the immediate post-test $(\mathrm{F}=2.03 ; \mathrm{p}=0.115)$ for the three groups.

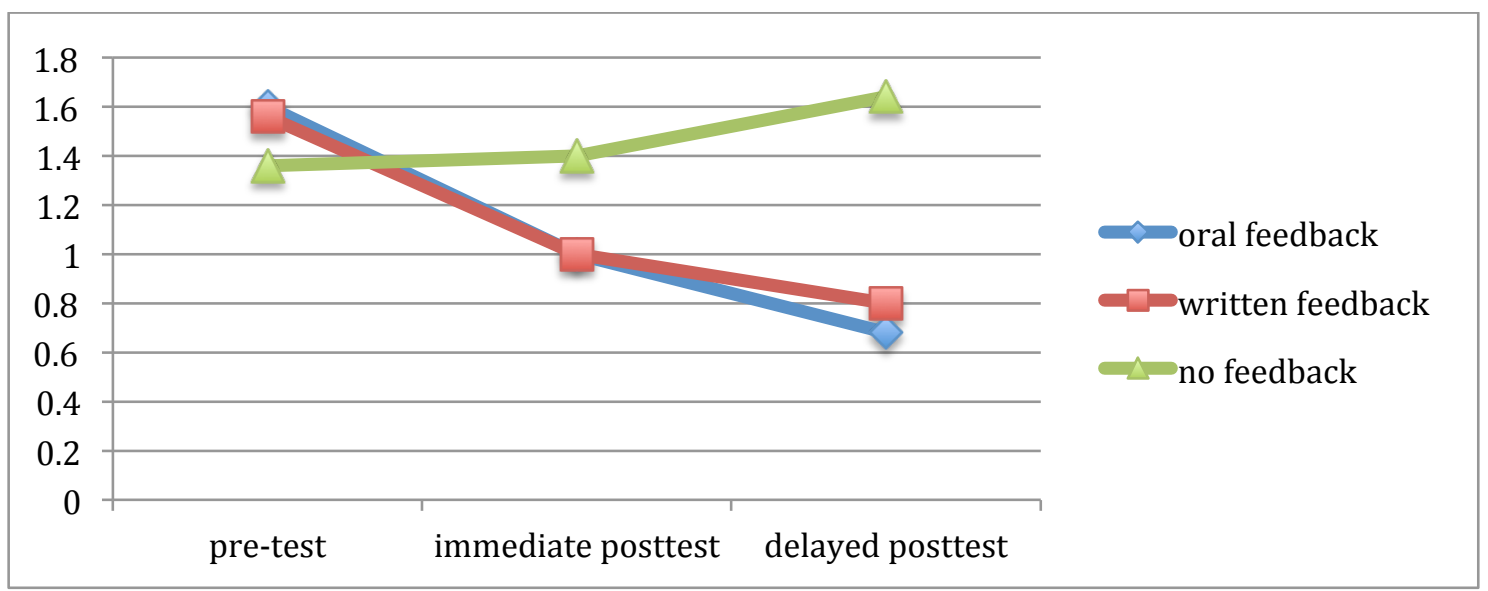

FIGURE 4. Group means for the use of past tense errors across the three treatment groups over time 
Figure 4 shows the mean number of past tense errors in all three groups decreased immediately after receiving the first and second feedback interventions. However, Group 3 did not reduce its considerable number of past tense errors in the two post-tests. A one-way ANOVA revealed significant differences in the mean number of past tense errors of the three groups $(F=3.82 ; \mathrm{p}=0.010)$, but no difference between Groups 1 and 2 showed in the number of past tense errors $(F=0.031 ; p=0.97)$. The ANOVA further revealed significant differences among the three groups in the delayed post-test $(F=9.47 ; p=0.000)$ but not in the immediate post-test $(F=2.03 ; p=0.115)$. Pairwise comparisons further revealed significant differences between Group 3 and Groups $1(p=0.000)$ and $2(p=0.000)$ in the delayed posttest.

\section{DISCUSSION}

The findings of the research support past studies (Bitchener, Young \& Cameron 2005; Bitchener \& Knoch 2008, 2009a; 2010) in the argument that teacher feedback is an effective measure to improve the writing accuracy of English language competence over time. The results of this study are significant because they the shortcomings of previous research. This study is a step forward from many previous findings (e.g. Bitchener, Young \& Cameron 2005; Bitchener 2008; 2009a, 2010b), which did not include a self-correction/revision stage by the learners themselves after receiving teacher feedback. Feedback plus learner correction may have helped the learners to identify the errors made, although they may not have known the reason why they were producing errors. Hence, although learners were aware of errors, they cannot remove them.

These findings could be significant for the target population in Pakistan to tackle several problems in the teaching-learning context that affect their accuracy levels. Student editing could be important especially in the Pakistani context, where teachers are mostly responsible for editing their students' writing, which is time-consuming (Haider 2012). Learners are not obliged to review their writing by focusing on their teacher's correction nor do they correct their past errors before producing a new piece of writing. Hence, students do not focus on eliminating mistakes or on making progress in the written accuracy of these structural areas.

From a theoretical point of view, improved accuracy in the immediate and delayed post-test may suggest evidence of uptake. Students noticed and understood the feedback and the differences and mismatches between their output and the target-like version are provided in the form of feedback (Swain 1995). This strategy could help them reformulate, modify and internalize their production, which ultimately leads to language acquisition. Afterwards, through practice, the explicit knowledge given in the form of feedback could benefit students' procedural ability to use linguistic forms accurately more widely. Thus, this research suggests evidence for an interface position between implicit and explicit knowledge, according to skill acquisition theory (DeKeyser 2007).

Students in this study were likely to have been familiar with the use of the targeted forms, although they may have had limited practice, at the beginning of the study and had received prior instruction relating to these forms. This situation suggests that learners had been prepared to attempt to follow the feedback provided for their writing and that feedback was approximately aligned to their current level of development (which was determined through the result of their grammar assessment) as prior requirement of the study (Pienemann 1989). However, the feedback would probably not have been effective if a large range of error categories had been targeted or were provided the features outside their ZPD (in terms of Vygotsky's socio-cultural theory). 
The categories that improved in accuracy over time were article and past tense use errors. The prepositional errors appeared to remain constant over all the written exercises and neither Groups 1 or 2 (who received feedback) improved and nor did Group 3 make any significant improvement in preposition errors. The findings for article forms in this study supported previous research (i.e. Bitchener, Young, \& Cameron 2005; Bitchener 2008) which showed improvement in article production in the results for the delayed post-intervention production. This result thus supports the view that not all errors can be eradicated in the same manner. Some errors are easier to correct than others, and these errors are usually considered treatable because of being rule-governed, like articles and past tense verbs (Truscott 1999). The effect of feedback can vary from learner to learner and depend on the linguistic domain of the error categories feedback aims to correct and the ZPD of the learner. Article and past tense errors are treatable errors according to Ferris (1999), whilst preposition errors are untreatable error (unless they can be broken down into subcategories of time, place, etc. with an appropriate picture prompt for creative writing to be produced using them). This notion was reflected in the results, which exhibited the differences in the effectiveness of the feedback targeting the three linguistic structures. Furthermore, students were at an early stage of their English language course at the university. Thus, the mastery of untreatable errors probably requires more detailed understanding of English language over a longer period.

Nevertheless, these findings provide counter-evidence for Truscott's (1996) argument that corrective feedback is discouraging and harmful for learners' writing, and error feedback only results in pseudo-learning. The findings of this study suggested that on the whole, the level of accuracy of treatable errors improved across the three sets of writing texts. That is, no linear development from one test to the other occurred. If only pseudo-learning had taken place or through general instruction alone, the effectiveness of the feedback intervention would not have been so durable.

The findings indicated that Group 1 (who received oral meta-linguistic explanation) performed well in two of the three linguistic forms in the post-intervention writing samples. The analysis of individual categories found that for past tense errors, Groups 1 and 2 feedback intervention groups significantly improved their accuracy compared to Group 3 in the delayed post-test. However, in the case of articles, only Group 1 outperformed the control group in the new sample of writing. Preposition errors remained largely unchanged in all three groups over the three writing exercises. This result might be due to the use of the past tense and articles being substantially rule-governed and thus, these areas are more treatable, whilst the use of prepositions is more idiosyncratic and is less treatable (Ferris 1999).

The findings of the second research question that Group 1 had two opportunities, i.e. two short oral feedback sessions (before the immediate and delayed writing), to discuss their mistakes with the researcher and language teacher. The teacher explained the rules with the help of different instances to help learners notice and compare the mismatches between their errors and the target through the feedback they received. Moreover, in socio-cultural theory, the feedback provided during the interaction or scaffolding between the researcher/teacher (or expert) and students (or novices) was effective for the improvement of the appropriate forms. The language teacher, in this case, guided the novices by illuminating their existing knowledge of linguistic forms and pushing the learners to a higher level of development. This error-feedback method can help students become self-reliant and make significant changes themselves by taking more charge of their learning and reducing the errors they make when producing new pieces of writing.

The findings concerning the articles, in the current study, support the earlier works of Bitchener, Young and Cameron (2005) and Bitchener and Knoch (2010b). In the current study, oral metalinguistic explanation in the form of a mini-lesson lasted for 15 to 20 minutes. This mini-lesson was found equally effective as the more time-consuming 
metalinguistic conferences undertaken in Bitchener (2008) and Bitchener and Knoch (2008), which lasted 30 minutes, Bitchener, Young and Cameron's (2005) time consuming one-toone student-researcher conferences that lasted 5 minutes, and Bitchener and Knoch (2010b) that lasted 15 minutes. Large classes and limited class time made one-to-one conferences untenable.

The findings concerning article errors differed from the findings of Bitchener (2008) and Bitchener and Knoch (2008). Groups 1 and 2 outperformed Group 3, which did not receive any feedback at all. The reason might be that, unlike Bitchener, Young and Cameron's and the current study, Bitchener (ibid) and Bitchener and Knoch (ibid) used a more specific and focused approach by providing feedback on just two functional uses of the article. In the current study, students had to take notice of three structural forms at a time rather than focusing on a single linguistic form to trigger their implicit knowledge and lead to learning acquisition.

\section{CONCLUSION AND LIMITATION}

Feedback affects the developing accuracy of the targeted forms, but these effects were mainly for improving the accurate use of treatable error categories (i.e. article and past tense) and not of untreatable errors (i.e. prepositions) over time. Moreover, Group 1 outperformed the control group by improving the accuracy of all two targeted linguistic forms in new pieces of writing. In-depth analysis showed that Groups 1 and 2 performed better than Group 3 in reducing article errors in the delayed post-test. The two feedback receiving groups ( 1 and 2$)$ performed better than Group 3 in improving the accuracy of past tense forms over time. However, no group improved the accuracy of their prepositional use over time. Only Group 1 significantly reduced the number of article errors and little improvement in past tense but not preposition errors over time was observed.

Acknowledging limitations of this study for future research is important. The study focused on partially-known linguistic forms/structures. Before the start of this study, students were taught the rules of using these three grammatical forms along with other forms for which they did not have full mastery on their use. Given this context, further research is needed to examine whether the acquisition of new features that learners have not been previously taught could be supported through these types of feedback. Further research is required to determine whether the improvement reported by the present study from oral metalinguistic explanation is retained over a more extensive period of investigation and to determine whether the type, frequency, amount and delivery of meta-linguistic explanations are factors in any of the observed differences.

Another limitation is the duration of this quasi-experimental study. This study measured the retention of accuracy in over three months, but the results would be significant if future researchers extended this scope to involve different post-tests over a longer period such that the ultimate importance of feedback for written acquisition could be estimated. The relative effect of different feedback types used in the present study could have been observed more clearly by extending the time period to 10 months as Bitchener and Knoch (2010a) did. However, due to the constraints of the availability of the participants and their teachers, this study could not last longer than three months.

The use of the same type of writing task (like the picture description task in this study) on three occasions might be considered a limitation because the task did not include opportunities for learners to demonstrate their capabilities to perform at the same level of accuracy when writing in other genres. Future research might, therefore, want to include such opportunities in at least one of their delayed post-tasks. 
In this study, free writing was based on picture prompts to provide a context to encourage the learners to produce the targeted forms, even about topics which the learners were uncertain. Less action and topic control, unlike the pictures prompts, could have led to avoidance of the targeted forms and given lower error rates and not revealed the students' implicit knowledge of these forms. The examples of the three forms showed that learners mostly avoided using them, in spite of the picture contexts for the tested structures. Using picture sequence story prompts were thought to offer less chance of the learners avoiding the use of the targeted forms (Ellis 2005; Norris \& Ortega 2000). Hence, future research would do well to require students on all testing occasions to undertake freely constructed writing tasks as well as controlled constructed responses to the three targeted forms.

Despite these limitations, pedagogical recommendations can be offered. For example, mini-lessons can be provided to all students on a small range of recurrent error categories, followed by small group meta-linguistic sessions to discuss those specific errors that students found most difficult. Providing individual oral feedback to each student can be helpful as well. Teachers can set a five to six minute teacher-student oral meta-linguistic conference or tutorial. Further, teachers' attention and consistent feedback on untreatable errors (like prepositions) might be helpful. The teachers should ask their students to do their revisions or self-corrections once they have received feedback from their teachers. The teachers can convert the language classroom into a learner-centred place for creative writing by introducing a variety of different tasks.

\section{ACKNOWLEDGEMENT}

This work was supported by the research fund provided by HEC (Higher Education Commission), Pakistan. I am very grateful to the reviewer of the manuscript.

\section{REFERENCES}

Aljaafreh, A. L. \&Lantolf, J. P. (1994). Negative feedback as regulation and second language learning in the zone of proximal development. The Modern Language Journal, 78(4), 465-483.

Bialystok, E. (1994). Representation and ways of knowing: Three issues in second language acquisition. Implicit and explicit learning of languages, 549-569.

Bitchener, J. (2008). Evidence in support of written corrective feedback. Journal of Second Language Writing, 17(2), 102-18.https://doi.org/10.1016/j.jslw.2007.11.004

Bitchener, J. (2012). A reflection on the language learning potential of written CF. Journal of Second Language Writing, 21 (4), 348-363.https://doi.org/10.1016/j.jslw.2012.09.006

Bitchener, J. \& Knoch, U. (2008). The value of written corrective feedback for migrant and international students. Language Teaching Research, 12, 409-431.https://doi.org/10.1177/1362168808089924

Bitchener, J. \& Knoch, U. (2009a). The relative effectiveness of different types of direct written corrective feedback. System, 37(2), 322-329. https://doi.org/10.1016/j.system.2008.12.006

Bitchener, J. \& Knoch, U. (2010a). The contribution of written corrective feedback to language development: A ten month investigation. Applied Linguistics, 31, 193-214.

Bitchener, J. \& Knoch, U. (2010b). Raising the linguistic accuracy level of advanced L2 writers with written corrective feedback. Journal of Second Language Writing,19, 207-217.

Bitchener, J., S. Young. \& D. Cameron. (2005). The effect of different types of corrective feedback on ESL student writing, Journal of Second Language Writing, 14(3): 191-205.

Chandler, J. (2003). The efficacy of various kinds of error feedback for improvement in the accuracy and fluency of L2 student writing. Journal of Second Language Writing, 12, 267296.https://doi.org/10.1016/S1060-3743(03)00038-9.

Coleman, H. \& T. Capstick (2012). Language in education in Pakistan: Recommendations for policy and practice. British Council, 1_190.117, 127.

DeKeyser, R.M. (Ed.). (2007). Practice in a second language. Cambridge: Cambridge University Press.

DeKeyser, R.M. (2003). Implicit and explicit learning. In C. Doughty \& M. Long (Eds.), The handbook of second language acquisition (pp. 313-348). Oxford: Blackwell Publishing. Doughty\& Williams, 1998 
Ellis, R. (2004). The definition and measurement of L2 explicit knowledge. Language Learning, 54(2), 227275.

Ellis, R. (2005). Principles of instructed language learning. System, 33(2), 209-224.

Ferris, D. R. (1999). The case of grammar correction in L2 writing classes: A response to Truscott (1996). Journal of Second Language Writing 8(1), 1-11.

Ferris, D. R. (2004). The - grammar correction\| debate in L2 writing: Where are we, and where do we go from here? (and what do we do in the meantime . . .?) Journal of Second Language Writing, 13, 49-62. Ferris, D.R. (2010). Second language writing research and written corrective feedback in SLA: Intersections and practical applications. Studies in Second Language Acquisition, 32, 181-201.

Ferris, D. R. \& Roberts, B. J. (2001). Error feedback in L2 writing classes: How explicit does it need to be? Journal of Second Language Writing, 10, 161-184.

Fletcher, W. \& Birt, D. (1983). Storylines: Pictures sequences for language practice. Longman.

Guénette, D. (2007). Is feedback pedagogically correct? Research design issues in studies of feedback in writing. Journal of Second Language Writing, 16(1), 40-53.

Haider, G. (2012). An insight into difficulties faced by Pakistani student writers: Implications for teaching of writing. Journal of Educational and Social Research, 17.

Kepner, C. G. (1991). An experiment in the relationship of types of written feedback to the development of second language writing skills. Modern Language Journal, 75, 305-313.

Lalande, J. (1982). Reducing composition error: An experiment. Modern Language Journal, 66, 140-149. Long, M.H. (1996). The role of the linguistic environment in second language acquisition. In W. Ritchie \& T. Bhatia (Eds.), Handbook of second language acquisition. San Diego, CA: Academic Press.

Luan, N. L. \& Ishak, S. N. A. (2018). Instructor's Direct and Indirect Feedback: How do they Impact Learners' Written Performance?. 3L: Southeast Asian Journal of English Language Studies, 24(3).

Norris, J. \& Ortega, L. (2000). Effectiveness of L2 instruction: A research synthesis and quantitative metaanalysis. Language Learning, 50(3), 417-528.

Pienemann, M. (1989). Is language teachable? Psycholinguistic experiments and hypotheses. Applied Linguistics, 10, 52-79.

Polio, C., Fleck, C. \& Leder, N. (1998). - If only I had more timel: ESL learners' changes in linguistic accuracy on essay revisions. Journal of Second Language Writing, 7, 43-68.

Rahman, T. (1990). Pakistani English: The linguistic description of a non-native variety of English, Islamabad: National Institute of Pakistan Studies, Quaid-i-Azam University.

Robb, T., Ross, S., \& Shortreed, I. (1986). Salience of feedback on error and its effect on EFL writing quality.TESOL Quarterly, 20, 83-93.

Robins, L. S., Gruppen, L. D., Alexander, G. L., Fantone, J. C. \& Davis, W. K. (1997). A predictive model of student satisfaction with the medical school learning environment. Academy of Medicine, 72 (2), 134-9.

Sarwar, M., A. Shah, H. Alam. \& S. Hussian (2012). Usefulness and liking of English language as perceived by university students in Pakistan. Archives Des Sciences 65 (3), 114.

Schumann, J. H. (1978). The relationship of pidginization, creolization, and decreolization to second language acquisition. Language Learning, 28, 367-379.

Siddiqui, S. (2007). Rethinking Education in Pakistan: Perceptions, Practices, and Possibilities. Lahore: Paramount Publishing Press.

Sheen, Y. (2007). The effect of focused written corrective feedback and language aptitude on ESL learners' acquisition of articles, TESOL Quarterly, 41(2), 255-283. https://doi.org/10.1002/j.15457249.2007.tb00059.x

Swain, M. (1995). Three functions of output in second language learning. In G. Cook \& B. Seidlhofer (Eds.), Principle and practice in applied linguistics: Studies in honor of H. G. Widdowson (pp. 125-144). Oxford: Oxford University Press.

Truscott, J. (1996). The case against grammar correction in L2 writing classes. Language Learning, 46, 327369.

vanBeuningen, C., de Jong, N. H. \& Kuiken, F. (2012). Evidence on the effectiveness of comprehensive error correction in Dutch multilingual classrooms. Language Learning (forthcoming).

Vygotsky, L. (1978). Mind in society. Harvard University Press.85, 291. 